\title{
Cascade utilization of biomass: strategy for conversion of cellulose, hemicellulose, and lignin into useful chemicals
}

Aritomo Yamaguchi, ${ }^{* \dagger}$ Naoki Mimura,$^{\dagger}$ Masayuki Shirai $,{ }^{\dagger},+$ and Osamu Sato ${ }^{\dagger}$

†Research Institute for Chemical Process Technology, National Institute of Advanced Industrial Science and Technology (AIST), 4-2-1 Nigatake, Miyagino, Sendai 983-8551, Japan

Department of Chemistry and Biological Sciences, Faculty of Science and Engineering, Iwate University, Ueda 4-3-5, Morioka, Iwate 020-8551, Japan

Number of Pages: 2

Number of Figure: 1 

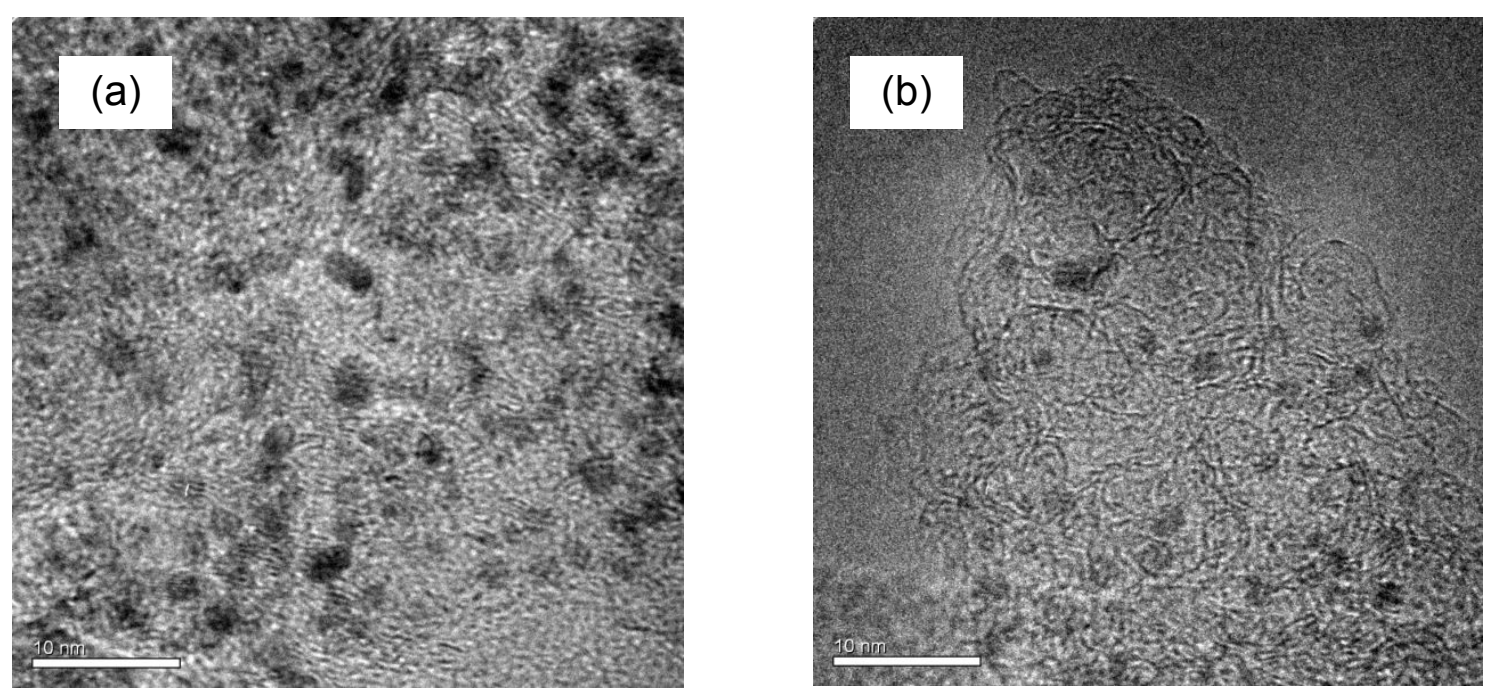

Figure S1. TEM images of $\mathrm{Pt} / \mathrm{C}$ catalyst (a) before the reaction and (b) after the last of four runs. 